\title{
Bite force and its correlation with long face in children and youth
}

\author{
J. Szymańska ${ }^{1}$, Ł. Sidorowicz ${ }^{2}$ \\ ${ }^{1}$ Chair and Department of Paedodontics, Medical University of Lublin, Poland \\ ${ }^{2}$ Chair and Department of Jaw Orthopedics, Medical University of Lublin, Poland
}

[Received 2 November 2014; Accepted 8 January 2015]

\begin{abstract}
Background: Bite force is one of the indicators of proper functioning of the stomatognathic system, and its value may have diagnostic significance in disorders of the musculoskeletal system of facial bones. The aim of the study was to evaluate the relationship between gender and age, and bite force in patients with high-angle vertical relationship of jaws and cranial bases.

Materials and methods: The study group comprised 66 subjects aged 7-17 years, in whom the mandibular jaw base line and maxillary jaw-base line (ML-NL) angles were greater than $27^{\circ}$ and the mandibular jaw-baseline and the anterior cranial base line (ML-NSL) above 33', and a control group $(n=54)$ aged $7-16$ years, in which the ML-NL angles were $20.0 \pm 7.0^{\circ}$ and ML-NSL $28.0 \pm 5.0^{\circ}$. For measuring the bite force, a Japanese digital dynamometer Imada type ZPS-LM$-2000 N$ was used.

Results: In the study group no statistically significant correlation between the bite force and gender was shown, and in the control group the average bite force on the right side was significantly different for boys and girls, whereas for boys it was higher. In the study group the relationship between the age and average and maximum bite force on the right and left side was significant. In the group of people with a high-angle relationship of bases of jaws and skull no statistically significant correlation between the bite force and gender was shown.

Conclusions: The was no effect of gender on the bite force in all subjects up to 18 years of age, both in patients with a high-angle and normal relationship of bases of jaws and skull. In people with a high-angle relationship of bases of jaws and cranium masticatory forces increase with age. (Folia Morphol 2015; 74, 4: 513-517)
\end{abstract}

Key words: jaw biomechanics, jaw orthopaedics, bite, children, young people, gender differences

\section{INTRODUCTION}

Bite force is one of the indicators of proper functioning of the stomatognathic system, and its value is used to diagnose disorders of the musculoskeletal system of facial skeleton [8].

Many factors influence the value of the bite force. They include the extent of jaw opening (bite force is reduced with small opening), dental health (patients do not use the maximum force on the damaged teeth), place of testing (the bite force is much greater in molars compared with incisors), orthodontic treatment and patient involvement $[5,6,10]$. For this reason, it is difficult to compare the masticatory forces obtained by different researchers [8].

The study aimed to evaluate the relationships between gender and age, and the bite force in patients 
with high angular vertical relationship of bases of jaws and cranium.

\section{MATERIALS AND METHODS}

The study comprised 120 patients treated in the Chair and Department of Maxillofacial Orthopaedics, Medical University of Lublin. Patients aged 7-17 years volunteered to get diagnosis and possible orthodontic treatment. The research was approved by the Ethics Committee (Resolution no. KE-0254/9/2013). The study covered 60 boys and 60 girls. The average age was $12.2 \pm 1.7$ years, half of the population did not exceed 12 years of age.

The patients meeting the following criteria were enrolled in the study:

- no history of orthodontic treatment at the time of examination;

- lateral cephalometric analysis of the head;

- people generally healthy, with no malformations and disorders of the muscular system.

All the respondents were distributed into two groups. The angle between the mandibular jaw base line and maxillary jaw-base line (ML-NL) and the angle between the mandibular jaw-baseline and the anterior cranial base line (ML-NSL) according to Segner and Hasund standard analysis [12] were the basis for the division.

The study group (the ML-NL angles above $27^{\circ} \mathrm{C}$ and ML-NSL above $33^{\circ}$ ) comprised 66 patients ( $55 \%$ of all respondents) aged 7-17 years, and half of them did not exceed 12 years, the average age was $12.2 \pm$ \pm 1.6 years.

The control group (the ML-NL angles $20.0 \pm 7.0^{\circ}$ and ML-NSL $28.0 \pm 5.0^{\circ}$ ) comprised 54 people ( $45 \%$ of all respondents) aged 7-16 years, half of them did not exceed 12 years of age (mean age $12.3 \pm 1.8$ years).

The bite force was assessed using a digital force gauge of Japanese company Imada, type ZPS-LM$-2000 \mathrm{~N}$ graduated in Newtons - N (unit of force in the $\mathrm{SI}$ ). The range of the instrument operation was 1-2000 N. The measurement was taken at the level of the first permanent molars. The patients were in- structed to bite the prepared sensor with maximum force. The force gauge in the operating mode "peak" stores and displays the highest recorded value. The measurement was repeated 5 times at 2-min intervals, for both the right and left side. The study considered the highest recorded value (maximum bite force) and the average of all measurements. The results were expressed in Newtons (N).

The cephalometric lateral images of head were performed using X-ray PLANMECA by PROSCAN with the voltage $70 \mathrm{kV}$ and exposure time $0.65 \mathrm{~s}$ with the lamp set at a distance of $1.52 \mathrm{~m}$ from the patient's head. Sagittal plane was parallel to the X-ray film. Images were taken in the right-side with the positioning of head in a natural position. Roentgenograms were subjected to cephalometric analysis. For this purpose, a computer program by Ortobajt Company was used where the required cephalometric points were defined on monitor screen. Then, by reading the marked points, the program conducted a cephalometric analysis. There was also made a freehand marking of some of measuring points with a pencil on a tracing paper with a thickness of $0.3 \mathrm{~mm}$.

\section{Statistical analysis}

The results were statistically analysed. The values of the analysed parameters, measured in nominal scale were characterised by cardinality and percentage. To find out the existence of differences between the two analysed groups for quantitative traits, Student $\mathrm{t}$-test for independent variables was used. To determine the correlation between age and bite force, the Spearman rank correlation coefficient test was used. To demonstrate the relationship between the measured traits, a test of the Pearson correlation coefficient was used and for the statistically significant relationships, regression lines were determined. There was a $5 \%$ error of inference and the associated significance level of $p<0.05$, indicating the existence of statistically significant relationships or differences.

Table 1. The relationship between bite force and gender in the control group

\begin{tabular}{lcccc}
\hline $\begin{array}{l}\text { Comparative analysis of the aver- } \\
\text { age of bite force of boys and girls }\end{array}$ & $\begin{array}{c}\text { Average bite } \\
\text { force for boys [N] }\end{array}$ & $\begin{array}{c}\text { Average bite } \\
\text { force for girls [N] }\end{array}$ & Test result & $\begin{array}{c}\text { Statistical } \\
\text { significance }\end{array}$ \\
\hline Average bite force on the left side & 288.7 & 290.6 & $\mathrm{t}=-0.09 ; \mathrm{p}=0.93$ & Insignificant \\
Average bite force on the right side & 309.04 & 259.08 & $\mathrm{t}=-2.17 ; \mathrm{p}<0.05$ & Significant \\
Maximum bite force on the left side & 343.03 & 338.5 & $\mathrm{t}=0.198 ; \mathrm{p}=0.84$ & Insignificant \\
Maximum bite force on the right side & 363.18 & 318.08 & $\mathrm{t}=1.81 ; \mathrm{p}=0.08$ & Insignificant \\
\hline
\end{tabular}

$\mathrm{N}$ - unit of force; $\mathrm{t}$ - value of the test function; $\mathrm{p}$ - level of significance 
Table 2. The relationship between bite force and gender in the study group

\begin{tabular}{lcccc}
\hline $\begin{array}{l}\text { Comparative analysis of the average } \\
\text { of bite force of boys and girls }\end{array}$ & $\begin{array}{c}\text { Average bite } \\
\text { force for boys }(\mathbf{N})\end{array}$ & $\begin{array}{c}\text { Average bite } \\
\text { force for girls }(\mathbf{N})\end{array}$ & Test result & $\begin{array}{c}\text { Statistical } \\
\text { significance }\end{array}$ \\
\hline Average bite force on the left side & 293.8 & 261.1 & $\mathrm{t}=1.22 ; \mathrm{p}=0.23$ & Insignificant \\
Average bite force on the right side & 291.1 & 243.8 & $\mathrm{t}=1.57 ; \mathrm{p}=0.12$ & Insignificant \\
Maximum bite force on the left side & 345.9 & 316 & $\mathrm{t}=0.98 ; \mathrm{p}=0.33$ & Insignificant \\
Maximum bite force on the right side & 344,8 & 289 & $\mathrm{t}=1.63 ; \mathrm{p}=0.11$ & Insignificant \\
\hline
\end{tabular}

$t$ - value of the test function; $p$ - level of significance

Table 3. The relationship between bite force and the age in the study group

\begin{tabular}{lcc}
\hline Studied parameters & Test result & Statistical significance \\
\hline The relationship between the average bite force on the & $t=2.14 ; p<0.05 ;$ & Significant \\
left side and the age in tested person & $r=0.26$ & Significant \\
$\begin{array}{l}\text { The relationship between the average bite force on the } \\
\text { right side and the age of tested person }\end{array}$ & $t=2.24 ; p<0.05 ;$ \\
$\begin{array}{l}\text { The relationship between the maximum bite force on the } \\
\text { left and the age of tested person }\end{array}$ & $t=2.15 ; p<0.05 ;$ \\
$\begin{array}{l}\text { The relationship between the maximum bite force on the } \\
\text { right and the age of tested person }\end{array}$ & $t=0.26$ & Significant \\
\end{tabular}

$t$ - value of the test function; $p$ - level of significance; $r$ - Pearson correlation coefficient

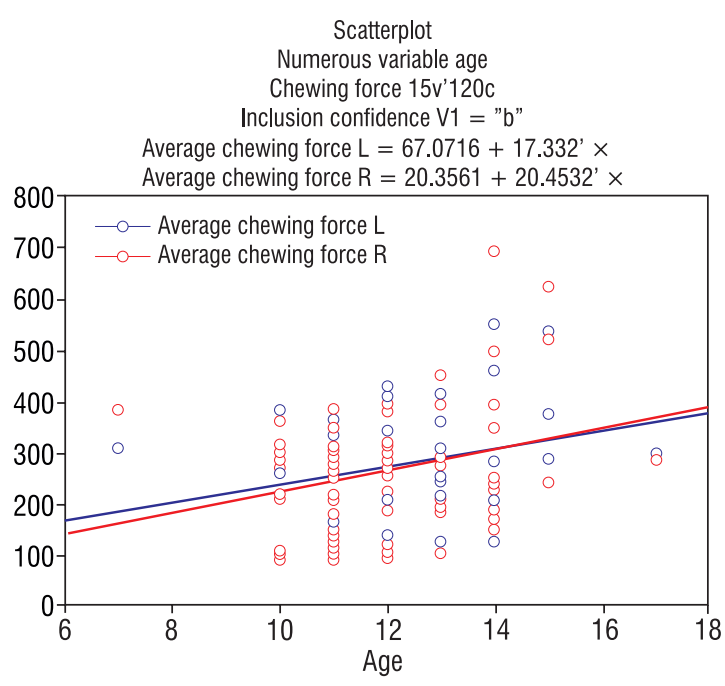

Figure 1. The effect of age on the average bite force on the left and right side in the study group.

Database of the analysed data and statistical analyses were performed based on the software Statistica 10.0.

\section{RESULTS}

In the control group (54 patients) and study group (66 patients), the relationship between the bite force and gender was examined. In the control group, the average bite force on the right side was significantly different for boys and girls, whereas for boys it was

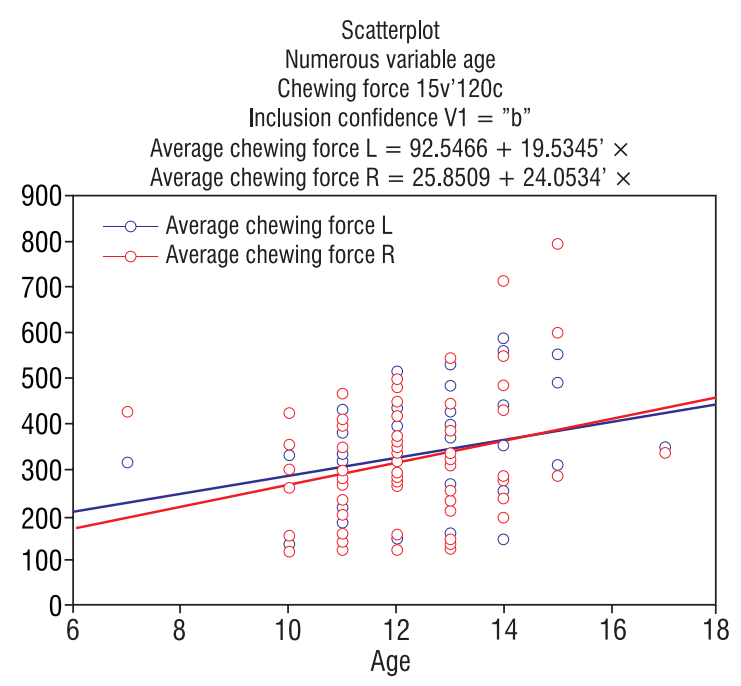

Figure 2. The effect of age on the maximum bite force on the left and right in the study group.

higher (Table 1). In the study group, no statistically significant correlation between the bite force and gender was showed (Table 2).

The relationship between bite force and age was also analysed. In the study group, there was a weak but statistically significant positive correlation between age and bite force. With the progressing age of the respondents, the value of bite force increased (Table 3). 
Table 4. The relationship between bite force and age in the control group

\begin{tabular}{lc}
\hline Studied parameters & Test result \\
\hline The relationship between the average bite force on the left and the age of tested person & $t=0.34 ; p=0.73 ; r=0.048$ \\
The relationship between the average bite force on the right and the age of tested person & $t=1.13 ; p=0.27 ; r=0.15$ \\
The relationship between the maximum bite force on the left and the age of tested person & $t=0.45 ; p=0.65 ; r=0.062$ \\
The relationship between the maximum bite force on the right and the age of tested person & $t=1.17 ; p=0.25 ; r=0.16$ \\
\hline
\end{tabular}

$t$ - value of the test function; $p$ - level of significance; $r$ - Pearson correlation coefficient

The assessment of the regression coefficient of the age variable indicates that with the increase of respondent's age, an increase in average bite force on the left by $17.3 \mathrm{~N}$ and by $20.5 \mathrm{~N}$ on the right side can be expected (Fig. 1).

However, for maximum bite force on the left and right side the regression coefficients with age variable indicate that with increasing age by 1 year of the surveyed, the increase in the maximum bite force on the left side on average by $19.6 \mathrm{~N}$ and on the right side on average by $24 \mathrm{~N}$ should be expected (Fig. 2).

In the control group, no statistically significant correlation between the variables was confirmed (Table 4).

\section{DISCUSSION}

Our study showed that gender has only a weak $(p=0.03)$ effect on the average bite force on the right side in the control group. A lack of clinical correlation between bite force and gender in the study population can therefore be presumed. Also Pereira et al. [11] did not confirm the relationship between the bite force and gender of patients (101 of the surveyed aged 6-18 years). Research by Linderholm et al. [9], which was carried out in a group of 12-year-old, did not confirm statistically significant difference between the values of bite force and gender. Similarly Sonnesen et al. [15] found no correlation between these variables. However, numerous studies in adults showed the difference in bite force based on gender $[3,4,6]$. Research by Braun et al. [4] and Varga et al. [20] suggested that up to 18 years of age, masticatory forces are similar in both sexes. After this period, the bite force increases in men. These results confirmed the findings of Tanner et al. [16], in which the cause of muscle mass increase in men is the discharge of corticosteroids after puberty. Tuxen et al. [17] perceive the difference in the bite force in adult patients based on gender in a larger number and thickness of type II fibres in males. However, there are reports confirming the lack of correlation between gender and the values of masticatory forces in adults [1].

In the study group in our material, a weak significant relationship between the bite force and age was shown. A similar correlation is not found in the control group. The increase in age in the test-group patients by 1 year, results in an increase of the maximum bite force on the left side on average by $19.6 \mathrm{~N}$, and on the right side on average by $24 \mathrm{~N}$. In the case of the average masticatory forces on the left side such increase is $17.3 \mathrm{~N}$, and on the right side $-20.5 \mathrm{~N}$. Usui et al. [18] showed in their work the increase in the value of masticatory forces with age. According to Bakke [2], bite force increases with age to about 12 years of age, then maintains at a similar level to 40-50 years of age, and then decreases. Research by Pereira et al. [11], which was conducted in paediatric patients (6-18 years old), also showed that the value of masticatory forces is dependent on age. Shinogaya et al. [13] assessed the effect of age on bite force in young (20-26 years) and elderly (53-62 years) Japanese subjects. They showed significantly higher values of masticatory forces in older patients, similar to those previously reported by Braun et al. [4]. The relationship between bite force and age was shown by Sonnesen and Bakke [14], but only in the case of females [2]. Ingervall and Minder [7] reported similar observations previously in their work, in contrast to research by Varga et al. [20], wherein the relationship between bite force and age occurred only in boys. It should be noted that in most of the studies there was a poor statistical significant correlation between these variables, indicating a relatively small effect of age on bite force [19].

\section{CONCLUSIONS}

The was no effect of gender on the bite force in all subjects up to 18 years of age, both in patients with a high-angle and normal relationship of bases of jaws 
and skull. In people with a high-angle relationship of bases of jaws and cranium masticatory forces increase with age.

\section{REFERENCES}

1. Abu Alhaija ES, Al Zo'ubi IA, Al Rousan ME, Hammad MM (2010) Maximum occlusal bite forces in Jordanian individuals with different dentofacial vertical skeletal patterns. Eur J Orthod, 32: 71-77.

2. Bakke M (2006). Bite force and occlusion. Semin Orthod, 12: $120-126$.

3. Bakke M, Holm B, Jensen BL, Michler L, Möller E (1990) Unilateral, isometric bite force in 8-68-year-old women and men related to occlusal factors. Scand J Dent Res, 98: 149-158.

4. Braun S, Bantleon HP, Hnat WP, Freudenthaler JW, Marcotte MR, Johnson BE (1995) A study of bite force. Part 1: relationship to various physical characteristics. Angle Orthod, 65: 367-372.

5. Fields HW, Proffit WR, Case JC, Vig KW (1986) Variables affecting measurements of vertical occlusal force. J Dent Res, 65: 135-138.

6. Helkimo E, Carlsson GE, Helkimo M (1977) Bite force and state of dentition. Acta Odontol Scand, 35: 297-303.

7. Ingervall B, Minder C (1997) Correlation between maximum bite force and facial morphology in children. Angle Orthod, 67: 415-422.

8. Koc D, Dogan A, Bek B (2010) Bite force and influential factors on bite force measurements: a literature review. Eur J Dent, 4: 223-232.

9. Linderholm $H$, Lindqvist $B$, Ringqvist $M$, Wennström $A$ (1972) Isometric bite force in children and its relation to body build and general muscle force. Acta Odontol Scand, 29: 563-568.

10. Molin C (1972) Vertical isometric muscle forces of the mandible. A comparative study of subjects with and wit- hout manifest mandibular pain dysfunction syndrome. Acta Odontol Scand, 30: 485-499.

11. Pereira L, Pastore MG, Bonjardim LR, Castelo PM, Gaviăo MB (2007) Molar bite force and its correlation with signs of temporomandibular dysfunction in mixed and permanent dentition. J Oral Rehabil, 34: 759-766.

12. Segner D, Hasund A (1996) Indywidualna kefalometria. Med Tour Press International, Warszawa.

13. Shinogaya T, Bakke M, Thomsen CE, Vilmann A, Sodeyama A, Matsumoto M (2001). Effects of ethnicity, gender and age on clenching force and load distribution. Clin Oral Investig, 5: 63-68.

14. Sonnesen L, Bakke M (2005) Molarbite force in relation to occlusion, craniofacial dimensions, and head posture in pre-orthodontic children. Eur J Orthod, 27: 58-63.

15. Sonnesen L, Bakke M, Solow B (2001) Bite force in pre-orthodontic children with unilateral crossbite. Eur J Orthod, 23: 741-749.

16. Tanner JM, Healy MJ, Whitehouse RH, Edgson AC (1959) The relation of body build to the excretion of 17-ketosteroids and 17-ketogenic steroids in healthy young men. J Endocrinol, 19: 87-101.

17. Tuxen A, Bakke M, Pinholt EM (1999) Comparative data from young men and women on masseter muscle fibres, function and facial morphology. Arch Oral Biol, 44: 509-518.

18. Usui $T$, Uematsu $S$, Kanegae $H$, Morimoto $T$, Kurihara $S$ (2007) Change in maximum occlusal force in association with maxillofacial growth. Orthod Craniofac Res, 10: 226-234.

19. van der Bilt A, Tekamp A, van der Glas H, Abbink J (2008) Bite force and electromyograpy during maximum unilateral and bilateral clenching. Eur J Oral Sci, 116: 217-222.

20. Varga S, Spalj S, LapterVarga M, Anic Milosevic S, Mestrovic S, Slaj M (2011) Maximum voluntary molar bite force in subjects with normal occlusion. Eur J Orthod, 33: 427-433. 